University of Nebraska - Lincoln

DigitalCommons@University of Nebraska - Lincoln

Faculty Publications, Department of Psychology

Psychology, Department of

December 1998

\title{
Parent Influences on Adolescent Peer Orientation and Substance Use: The Interface of Parenting Practices and Values
}

Karen Bogenschneider

University of Wisconsin-Madison, kpbogens@facstaff.wisc.edu

Ming-yeh Wu

Soochow University, Taipei

Marcela Raffaelli

University of Nebraska-Lincoln, mraffaelli1@unl.edu

Jenner C. Tsay

University of Wisconsin-Madison

Follow this and additional works at: https://digitalcommons.unl.edu/psychfacpub

Part of the Psychiatry and Psychology Commons

Bogenschneider, Karen; Wu, Ming-yeh; Raffaelli, Marcela; and Tsay, Jenner C., "Parent Influences on Adolescent Peer Orientation and Substance Use: The Interface of Parenting Practices and Values" (1998). Faculty Publications, Department of Psychology. 82.

https://digitalcommons.unl.edu/psychfacpub/82

This Article is brought to you for free and open access by the Psychology, Department of at DigitalCommons@University of Nebraska - Lincoln. It has been accepted for inclusion in Faculty Publications, Department of Psychology by an authorized administrator of DigitalCommons@University of Nebraska - Lincoln. 
Published in Child Development 69:6 (December 1998), pp. 1672-1688. Copyright $\subset 1998$ by the Society for

Research in Child Development, Inc. Published by Blackwell Publishing, Inc. Used by permission.

"The definitive version is available at http://www.blackwell-synergy.com/."

\title{
Parent Influences on Adolescent Peer Orientation and Substance Use: The Interface of Parenting Practices and Values
}

\author{
Karen Bogenschneider, University of Wisconsin-Madison \\ Ming-yeh Wu, Soochow University, Taipei \\ Marcela Raffaelli, University of Nebraska-Lincoln \\ Jenner C. Tsay, University of Wisconsin-Madison
}

\begin{abstract}
This study examines how experiences in the family domain may magnify or mitigate experiences in the peer domain, and how processes in both milieus may influence adolescent substance use. The data derived from 666 European American mother-adolescent dyads and 510 European American father-adolescent dyads. Consistent with individuation-connectedness theory, mothers' responsiveness lessened their adolescents' orientation to peers, which, in turn, reduced adolescent substance use. This process was moderated by maternal values regarding adolescent alcohol use; that is, the relation of maternal responsiveness to adolescent substance use depended on the extent of maternal approval or disapproval of adolescent alcohol use. Among fathers, closer monitoring was directly associated with less adolescent substance use, with stronger effects among fathers who held more disapproving values regarding adolescent alcohol use. Theoretical, methodological, and pragmatic implications are given.
\end{abstract}

\section{INTRODUCTION}

Researchers have demonstrated the powerful role parents play in young children's peer relationships (Parke \& Bhavnagri, 1989). This body of evidence provides empirical support for Bronfenbrenner's $(1977,1979)$ theorizing about mesosystem influences on children's development, specifically, how proximal processes in one microsystem, the family, may impinge on children's relationships in another, the peer group. Most studies examining linkages between parents and peers have been conducted with younger children, concentrating almost exclusively on mothers' influence on children's social relationships (Belle, 1989), with scant attention to fathers' influence or adolescents' peer relationships. This study extends Bronfenbrenner's mesosystems framework to adolescence because of the rich potential this developmental period holds for advancing our understanding methodologically, pragmatically, and theoretically.

Methodologically, the substantive changes in adolescents' relationships with parents and peers, stimulated by the onset of puberty (Belsky, Steinberg, \& Draper, 1991; Fuligni \& Eccles, 1993; Muuss, 1988; Steinberg, 1987), make adolescence fertile ground for research on parentpeer linkages in light of Dearborn's maxim, "If you want to understand something, try to change it" (cited in Bronfenbrenner, 1977, p. 518). Adolescents' increasing susceptibility to peer influence and decreasing susceptibility to parental influence (Berndt, 1979; Steinberg \& Silverberg, 1986) provide what Bronfenbrenner referred to as "an experiment of nature" (1977, p. 519).

Pragmatically, we find it curious that studies of parental peer linkages in adolescence have received short shrift, given that ages 14 to 18 are the most stressful time for parents, who worry about such peer-related issues as their children's choice of friends, negative peer pressure, and involvement in deviant behaviors (Gecas \& Seff, 1990; Olson et al., 1983; Pasley \& Gecas, 1984; Small, Eastman, \& Cornelius, 1988; Steinberg, 1990). Yet little is known about whether parents act on these concerns by attempting to manage adolescents' social relationships, and what strategies, if any, parents employ to foster positive peer affiliations and counteract negative influences. We find parents' decisions about whether to "buzz off" or "butt in" compelling (Brown, 1996), especially given the developmental overlay of adolescents' desire for more connection to peers and less dependence on parents. Parents who are too heavy-handed may infringe on what adolescents perceive as their legitimate purview (Smetana \& Asquith, 1994), whereas parents who are minimally involved may increase susceptibility to negative peer influence (Steinberg, 1990).

Finally, studies of parent-peer linkages may advance our theoretical understanding, given that developmental theorists paint a mixed picture of how much parenting practices can restrain adolescents' susceptibility to negative peer influence (Cooper \& Cooper, 1992; Steinberg \& Silverberg, 1986; Youniss \& Smollar, 1985). Although the evidence is inconclusive, three of the five prominent theo- 
retical traditions ("two social worlds," cognitive, and psychoanalytic) postulate that parents have a weak or limited capacity to protect their children from negative peer pressure. The other two prominent theories (socialization and individuation-connectedness) posit that parents wield a stronger, more substantial influence on their children's peer relationships.

The hypotheses of this study examine two pathways that derive from theories of strong connections between parenting practices and adolescent peer relationships; the rejection of our hypotheses, however, would support the alternative theories of weak parent-peer linkages. Because these linkages appear to vary across context (Brown, Mounts, Lamborn, \& Steinberg, 1993; Glynn, 1981; Kandel, Kessler, \& Margulies, 1978; Steinberg \& Brown, 1989), we examine one outcome, adolescent substance use, for methodological, theoretical, and pragmatic reasons. Methodologically, examining substance use is a conservative test of our hypotheses because studies suggest that peer influence on substance use is four times more potent than parental influence (Kandel \& Andrews, 1987). Theoretically, this focus may be an important window into parent-adolescent relationships because substance use is, for many adolescents, an arena where issues of autonomy are played out (Baumrind, 1967; Irwin \& Millstein, 1986). Pragmatically, adolescence is the period of greatest vulnerability for initiating substance use (McCord, 1990), a behavior that poses risk to the developing adolescent and potential harm to society (Bogenschneider, Wu, Raffaelli, \& Tsay, 1998; Hawkins, Catalano, \& Miller, 1992; Kandel et al., 1978; Newcomb \& Bentler, 1989).

Theories of Weak Parent-Peer Linkages during Adolescence

Recent studies cast doubt on the pessimistic predictions of the "two social worlds," cognitive, and psychoanalytic theories of parent-peer linkages, each of which is summarized here. (For a complete description, see Cooper \& Cooper, 1992, and Youniss \& Smollar, 1985.) In "two social worlds" theories, parents and peers are portrayed as operating primarily in isolation from each other. The influence of parents and peers is seen as distinct, with little or no overlap in the quality of relationships across the two settings (Berndt, 1979; Coleman, 1960; Greenberg, Siegel, \& Leitch, 1983; Hundleby \& Mercer, 1987; Kandel et al., 1978). Similarly, cognitive theorists such as Piaget (1932/1965) and Sullivan and Sullivan (1980) contended that social relationships with peers contribute to adoles- cent development in ways unique from those with parents. Parent relationships are based primarily on unilateral authority, in contrast with peer relationships, which are more equal and reciprocal. Thus, interactions with parents tend to be marked by conformity and obedience, whereas those with peers typically involve co-constructing reality, negotiating differences, and working toward consensus. Based on recent descriptions (see Collins, 1990, for an exception), cognitive theories are classified with the theories of weak linkages because adolescents are thought to manage their own development through their increased capacity for logically reflecting on their experiences and reaching valid conclusions (Youniss \& Smollar, 1985).

Psychoanalysts such as Freud (1958) and Blos (1979) predicted less parental influence on peer relationships during adolescence than in earlier developmental periods, attributable largely to the biological changes triggered by puberty. In response to anxiety-provoking sexual feelings toward parents, adolescents must detach (classical view) or individuate (contemporary view) from parents, irrespective of the closeness of early family ties. This severing of parental ties occurs before adolescents have developed sufficient capacity to function autonomously, which results in a rush from dependency on parents to dependency on peers (Steinberg \& Silverberg, 1986). Psychoanalysts consider this shift from parent to peer influence necessary for adolescent autonomy to develop on course.

\section{Theories of Strong Parent-Peer Linkages during Adolescence}

Recent studies have challenged views that adolescent detachment from parents is desirable (Mounts, 1996; Ryan \& Lynch, 1989; Steinberg, 1990; White, Speisman, \& Costos, 1983) or that parents' influence on their adolescents' peer relationships is weak or sharply curtailed (for an exception, see Brown \& Huang, 1995). Both the socialization and individuation-connectedness perspectives propose that parents influence their adolescents' peer relationships, albeit through different mechanisms.

Socialization theories (Clausen, 1968; Coleman, 1960) are generally portrayed as painting a dismal picture of parents' ability to transmit cultural values to adolescents and to overcome socialization by peers (Clausen, 1968; Youniss \& Smollar, 1985). Socialization theorists tend to emphasize the competition between these two opposing forces, which have been described aptly as "benevolent parents" and "malevolent peers" (Steinberg \& Brown, 1989, p. 2). Parents are thought to propel their adolescents into 
a peer counterculture by abdicating parental responsibility and trying to befriend their children, rather than acting as agents of socialization (Youniss \& Smollar, 1985). Yet an often overlooked corollary of this premise is that parents have the power to transmit their values and socialization goals to their offspring by restraining their adolescents' relationships with peers and monitoring their activities and whereabouts to protect them from negative peer influence (see Cooper \& Cooper, 1992).

Consistent with the tenets of this theory, parental monitoring is a strong deterrent to adolescent involvement in virtually any problem behavior (Lamborn, Mounts, Steinberg, \& Dornbusch, 1991; Patterson \& Stouthamer-Loeber, 1984; Snyder, Dishion, \& Patterson, 1986; Wu, 1995), although the evidence linking parental monitoring to peer orientation is less conclusive. One study reported an indirect effect of monitoring on substance use: Low parental monitoring increased the likelihood that adolescents associated with substance-using peers, which, in turn, encouraged substance use (Patterson, De Baryshe, \& Ramsey, 1989). In other studies, low parental monitoring was related to a peer orientation so extreme that 13- to 16-yearolds committed deviant acts (Barnes \& Farrell, 1992) and sixth and seventh graders abandoned parental rules, schoolwork, and even their own talents to be popular with friends (Fuligni \& Eccles, 1993).

Several recent studies suggest less oppositional and more contingent linkages between parents and peers (Steinberg, 1990). The individuation-connectedness perspective posits that individuation occurs optimally in the context of close relationships with parents (Youniss \& Smollar, 1985). Adolescents move toward independence from parents while, paradoxically, striving to remain connected to them. Thus, the transformation of the parent-adolescent relationship, rather than parental monitoring, is the mechanism through which parents influence peer relationships. If the relationship transforms from one based on unilateral authority to one of interdependence and cooperative negotiation (Cooper \& Cooper, 1992; Steinberg, 1990; Youniss \& Smollar, 1985), adolescents still seek parental advice, allowing continued parental influence over adolescent development and peer relationships.

In concordance with this theory, studies reveal that parents who fail to grant increasing decision-making opportunities or to relax power and restrictiveness have adolescents who become extremely peer-oriented at the expense of heeding parental rules (Fuligni \& Eccles, 1993). Moreover, parental responsiveness, often used as a measure of the closeness of the parent-adolescent relationship, is an important correlate of children's social competence and choice of friends (Brody \& Shaffer, 1982; Kandel \& Andrews, 1987; Lamborn et al., 1991). In a study of high school students, parental closeness discouraged drug use directly and also indirectly through the choice of non-drugusing friends (Kandel \& Andrews, 1987).

Thus, the influence of parents and peers is portrayed as more interdependent and less antagonistic by individuation-connectedness theorists than socialization theorists, implying that adolescents' involvement with both parents and peers may be optimum for healthy development. Based on recent studies, simultaneous influence from parents and peers is not contradictory (Greenberg et al., 1983); adolescents performed best on a range of outcomes when both parents and peers were supportive, and much worse when neither was supportive (Brown et al., 1993; Brown \& Huang, 1995; Kandel, 1986; Kandel \& Andrews, 1987; Ryan \& Lynch, 1989; Steinberg \& Brown, 1989). Furthermore, observational studies reveal that communication patterns with parents and peers do not conflict as cognitive theorists have predicted; instead, interaction patterns in the family carry over to adolescent negotiation with peers (Cooper \& Cooper, 1992).

\section{The Context in Which Parenting Practices Operate}

Little is known about how the effectiveness of parenting practices may be moderated by characteristics of the environment or the person (Darling \& Steinberg, 1993), such as the values that underlie parents' socialization goals. According to Miller (1993), values are deeply held and enduring standards about right and wrong, about what "ought to be." Darling and Steinberg (1993) cited scholars as early as 1939 who argued that parents' values are important determinants of parenting behavior, which was demonstrated convincingly in Kohn's seminal work in 1969. Since then, however, studies have been sparse. In a recent exception, mothers who placed a higher value on prosocial behaviors, specifically early adolescents' sociability, perceived their children's social behaviors more accurately and devoted more time to promoting their children's peer relationships, but only if they believed parents could be an important influence (Cohen \& Woody, 1991). Recent studies suggest that parents may also influence their offspring through the values they hold regarding risky behaviors. For example, studies have consistently reported that permissive parental attitudes and values about adolescent alcohol use are a strong predictor of adolescent substance use (Ary, Tildesley, Hops, Lichtenstein, \& Andrews, n.d.; Barnes \& Welte, 
1986; Kandel \& Andrews, 1987), even stronger than parents' own alcohol use (Ary et al., n.d.; Brook, Whiteman, Gordon, \& Cohen, 1986; Hawkins et al., 1992).

What remains unclear is how values influence parenting behavior. Do values define which practices parents will employ, as suggested by Darling and Steinberg (1993); that is, do values precede the adoption of specific parenting practices? Or do values serve in a moderating capacity; that is, are parenting practices more effective in influencing adolescent outcomes parents value highly?

\section{Plan of Analyses and Hypotheses}

In this study, we attempt to overcome several shortcomings of previous research on parent-peer linkages during adolescence. First, despite little overlap between parent and peer views of family dynamics (Carlson, Cooper, \& Spradling, 1991), parent-peer linkages have been studied primarily from the vantage point of the adolescent (Berndt, 1979; Brown et al., 1993; Brown \& Huang, 1995; Fuligni \& Eccles, 1993; Lamborn et al., 1991; Steinberg \& Brown, 1989; Steinberg \& Silverberg, 1986). This study also includes the perspective of parents, which seems important in a line of inquiry in which the influence of parents on their children's peer orientation is presumed to be stronger than the influence of peer orientation on parents' socialization practices (for an exception, see Brown et al., 1993).

Second, the specific practices through which parents are hypothesized to influence adolescent peer orientation are theory-driven. Based on the predictions of socialization theories, we hypothesize that parents influence their adolescents' peer relationships through parental monitoring. Consistent with individuation-connectedness theories, we hypothesize that parents influence their adolescents' peer relationships by being responsive to their adolescents. We focus on the pathways through which specific parenting practices influence peer relationships, rather than categorizing responsiveness and monitoring into a global parenting style (Baumrind, 1967; Ladd, 1992; Renshaw \& Parke, 1992). Although parenting style has proven powerful in predicting adolescent outcomes, it provides little insight into the processes whereby these influences occur (Belsky, Hertzog, \& Rovine, 1986).

Third, many studies have implicitly assumed that parenting practices linking the parent and peer domains are equally effective across all adolescent outcomes. Because the study of parent-peer linkages is in its infancy, this assumption is premature, especially in light of evidence that adolescents who reject parental advice and follow the lead of peers on substance use, for example, do not necessarily reject parental influence in other circumstances (Brown et al., 1993; Glynn, 1981; Kandel et al., 1978; Steinberg \& Brown, 1989). As a conservative test of our hypotheses, this study examines parent and peer influences on adolescent substance use, an outcome more heavily influenced by peers than parents (Kandel \& Andrews, 1987). Peer influence is the strongest predictor of adolescent substance use (Barnes, Farrell, \& Banerjee, 1994; Hawkins et al., 1992; Newcomb \& Bentler, 1989; Norem-Hebeisen, Johnson, Anderson, \& Johnson, 1984), even after taking into account the influence of parental support and monitoring (Barnes \& Farrell, 1992).

The data are analyzed using path analysis, which allows us to examine our hypotheses about the direct and indirect effects of the parenting variables in the model. Specifically, this analysis allows us to disentangle whether parenting practices influence adolescent substance use directly or indirectly through their influence on adolescent peer orientation. As shown in Figure 1, we hypothesize that the influence of parental responsiveness and monitoring on adolescent substance use is indirect through their negative association with relative peer orientation, which, in turn, is associated positively with substance use. Moreover, we examine whether the hypothesized parenting practices have the same influence on adolescent substance use across the sample of parents or whether the influence is moderated by parental values regarding adolescent alcohol use. Specifically, we hypothesize that parental responsiveness and monitoring will be more potent in deterring adolescent substance use among adolescents of parents who strongly disapprove of adolescent alcohol use than among parents who are less disapproving. In accordance with Heise (1975), the moderators are illustrated as circles.

The mediating and moderating hypotheses are examined in one series of regression analyses, based on the premise that the combined model is perhaps the most potent analytic strategy for predicting social behavior (Baron \& Kenny, 1986). The path analysis is examined in six steps. In the first two steps, the dependent variable is regressed on the independent variables and then on the moderator. Third, the moderating hypothesis is tested by entering the interaction term, the product of each independent variable and the moderator (e.g., parental responsiveness times parental values), into the regression analyses after controlling for the main effects of the in- 


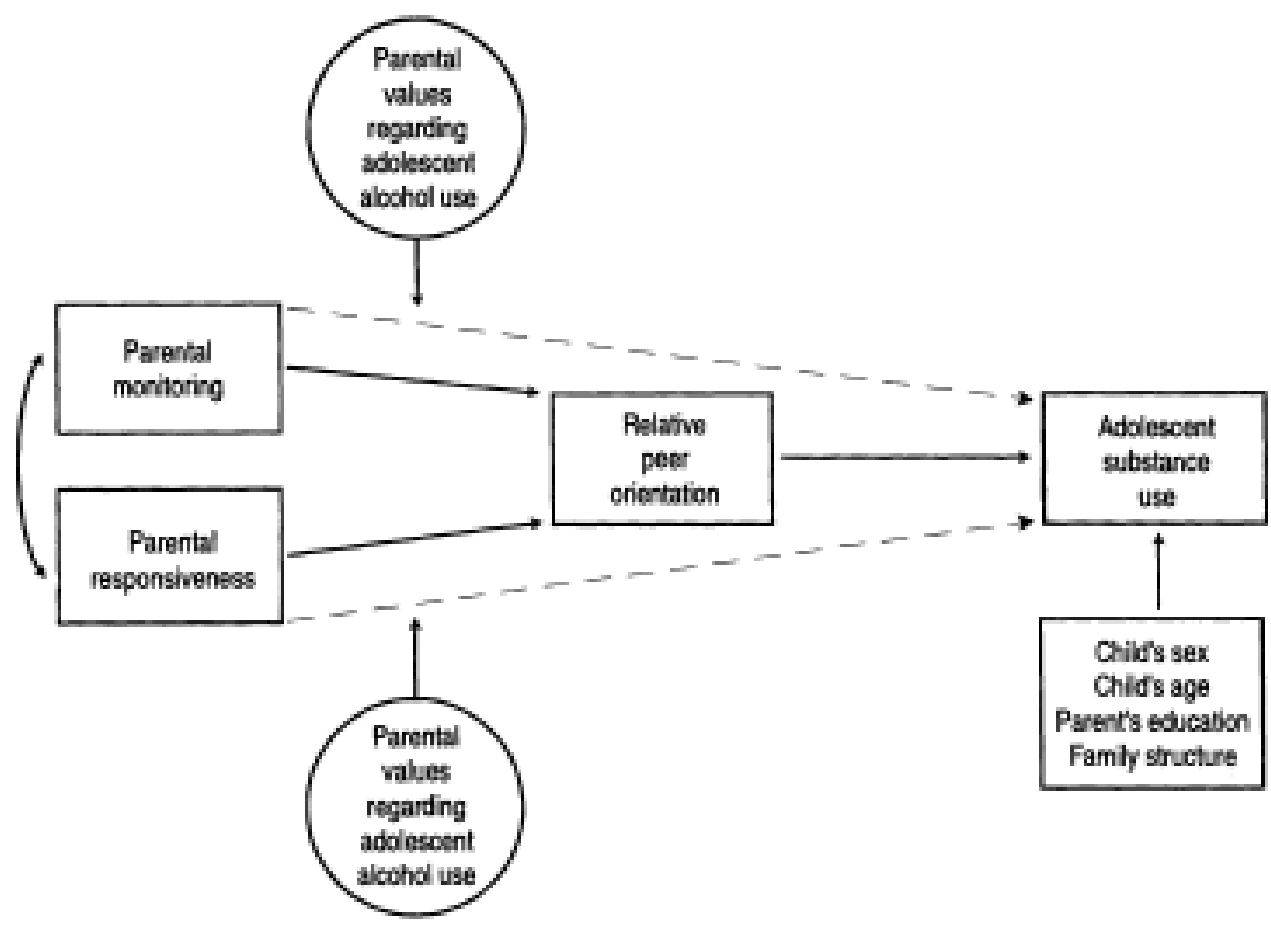

\begin{abstract}
Note: The solid lines represent the indirect effects of the parenting variables on adolescent substance use. The curved line indicates a correlation. The dashed lines indicate direct effects of the parent variables on adolescent substance use, which we expect to disappear after the mediating variable is taken into account. The circles represent the moderating variable.
\end{abstract}

Figure 1 The hypothesized model of how parenting practices and values influence adolescent peer orientation and substance use

dependent variables and the moderator (Baron \& Kenny, 1986; Cleary \& Kessler, 1982; Rosnow \& Rosenthal, 1989). Fourth, the hypothesized mediator is regressed on the independent variables. Fifth, the dependent variable is regressed on the mediator with the independent variables partialed out. Finally, the dependent variable is regressed on the independent variables, the moderator, and the mediator. For mediation to occur, the mediator must be significantly related to the independent variable and also to the dependent variable with the independent variable partialed out (Baron \& Kenny, 1986; R. Serlin, personal communication, April 29, 1998). The strongest evidence for a mediating effect emerges when the direct relation between the independent variable and the dependent variable or between the moderator and the dependent variable is no longer significant after the mediator is entered into the analysis. To minimize problems of multicollinearity in regression analyses with interaction terms, the independent and moderator variables are centered, which avoids bias in estimating the regression coefficients (Aiken \& West, 1991).

\section{METHOD}

\section{Sample}

The sample and procedures derived from a study of 1,227 students in eighth to twelfth grade and their parents, $N=$ 1,176 , from three school districts in urban, suburban, and rural settings in a Midwestern county between December 1994 and May 1995. The adolescent and parent samples and the data collection procedures are described in the following sections.

Adolescents. Students were administered a 160 item questionnaire in their classrooms. In two schools, all students in the target grades were surveyed; in two larger schools, a representative subset of classrooms was selected by school guidance personnel, taking into account the grade level and academic difficulty of the classes. Participation rates ranged from $84 \%$ to $96 \%$ across the schools; overall, $88 \%$ of enrolled students participated. Only 10 students provided unusable data, yielding 1,227 student participants, none of whom were siblings. 
Parents. Mothers and fathers were asked to complete a parallel 131-item mail survey. Mailing envelopes were pre-coded with the same identification number assigned to the target child. Parents were asked to complete a survey for their oldest child (in schools where all students participated) or a specific child (in schools where a subset of students took part). After two mailings, non-respondents were contacted by telephone and encouraged to participate. A total of 1,306 parents returned a survey, yielding a response rate of $60 \%$ after adjusting for single-parent households and families who had moved during the study. Response rates ranged from $55 \%$ to $66 \%$ in the three school districts. Of the returned surveys, 7 were blank, 45 had no matching data from the target adolescent, and 78 were completed for the wrong child; thus, 1,176 parents provided data that could be matched to a student survey.

Matched sample. The matched sample consisted of 666 mother-adolescent dyads ( 324 boys and 342 girls) and 510 father-adolescent dyads ( 260 boys and 250 girls). Of the adolescents, $66 \%$ reported on both parents. Based on selfreports, $97 \%$ of the mothers, $95 \%$ of the fathers, and $91 \%$ of the adolescents were European American. The average age was 15 for teens in both the mother and father samples, 42 for mothers, and 45 for fathers. In regard to family structure, $71 \%$ of the adolescents in the mother sample and $81 \%$ in the father sample reported living with two biological or adoptive parents, $12 \%$ of adolescents in the mother sample and $4 \%$ in the father sample lived in single parent families, $10 \%$ of adolescents in the mother sample and $11 \%$ in the father sample lived in stepfamilies, and the remainder lived in other arrangements. Based on parent reports, $25 \%$ of mothers and $20 \%$ of fathers had a high school education or less, $41 \%$ of mothers and $37 \%$ of fathers had some college or technical school, and $34 \%$ of mothers and $43 \%$ of fathers had a college degree or more. About $30 \%$ of mothers and $70 \%$ of fathers were employed $41 \mathrm{hr}$ or more per week, $40 \%$ of mothers and $24 \%$ of fathers were employed 32 to $40 \mathrm{hr}$ per week, and $21 \%$ of mothers and $2 \%$ of fathers were employed fewer than 32 hr per week; the rest were homemakers, in school, unemployed, disabled, or other.

\section{Measures}

The adolescent and parent surveys include items on family, peer, school, and community influences on adolescent development. Of interest in this study were substance use and peer orientation, measured from the adolescent perspective, and parental monitoring, responsiveness, and values regarding adolescent alcohol use, measured from the parent perspective. Based on criticisms that our knowledge of childrearing is based disproportionately on data from mothers (Minuchin, 1985), mothers' and fathers' responses were analyzed separately.

Adolescent-reported measures. To assess substance use, adolescents were asked how often in the past year they used eight substances: tobacco, beer, wine/wine coolers, hard liquor, marijuana, inhalants, hallucinogens, and cocaine/crack. Scores ranged from 0 , indicating never using the substance, to 5 , indicating daily use. The mean score was $.46, S D=.59$, in the mother sample and $.44, S D=.58$, in the father sample. The internal consistency, as determined by Cronbach's alpha, was .83 and .84 in the mother and father samples, respectively.

Two questions were used jointly to classify adolescents' level of relative peer orientation (high, moderate, or low). These questions do not force adolescents to choose between parents and peers, but rather allow adolescents to indicate that they rely on both. In the first question, adolescents are asked to choose from a list of 10 alternatives the one person, if anyone, they would talk to if they were having a personal problem; of these, 3 are parents or peers, consistent with our conceptualization, 6 are non-parental adults or a sibling, and 1 is "no one to talk with." In the second question, adolescents are asked if they have had at least one good talk with their parents about personal problems in the past year. Adolescents who chose to talk to friends and had never talked to parents regarding personal problems in the past year were classified as 3 , highly peeroriented. Adolescents who chose to talk to friends but also reported talking to parents were classified as 2 , moderately peer-oriented. Adolescents who chose to turn first to a parent were classified as 1 , low in peer-orientation, regardless of whether or not they had talked to parents.

Of the adolescents who chose a response of either parent or peer on the first question, $28 \%$ in the mother sample and $27 \%$ in the father sample were classified as highly peer-oriented, $44 \%$ in the mother sample and $42 \%$ in the father sample as moderate, and $28 \%$ in the mother sample and $31 \%$ in the father sample as low. The means were $2.00, S D=.75$, and $1.96, S D=.76$, in the mother and father samples, respectively. About one-fifth of the adolescents, $21 \%$ in the mother sample and $21 \%$ in the father sample, selected one of the seven other responses (e.g., teacher, coach, school counselor; minister, priest, rabbi; youth organization leader), which were irrelevant to the conceptualization of orientation to peers relative to parents. To examine whether dropping these cases in analyses 
that included peer orientation influenced the results, we compared the substance use of the two groups: students who selected a response of parent or peer and those who gave any other response. In an ANCOVA with controls for child's sex, child's age, parent's education, and family structure, adolescent substance use in either the mother or father samples did not vary depending on whether students turned first to a parent or peer or whether they turned to a sibling or non-parental adult.

Parent-reported measures. Parental responsiveness was assessed with six items adapted from Armsden and Greenberg's (1987) Inventory of Parent Adolescent Attachment. As proposed by Maccoby and Martin (1983), the scale measures not only parental warmth expressed toward the child (e.g., "I tell my child that I love him/her"), but also contingent responses and availability (e.g., "My child and I just spend time talking with each other"). Responses ranged from never (0) to always (4). The mean for mothers was $2.96, S D=.62$, and for fathers $2.57, S D=.66$. Cronbach's alpha yielded a reliability of .84 for mothers and .84 for fathers.

Parental monitoring was assessed via six items adapted from a scale by Small and Kerns (1993), which assesses the extent to which parents know their children's friends, the parents of their children's friends, and their children's whereabouts. Response categories range from never (0) to always (4). Consistent with previous studies (Barnes \& Farrell, 1992; Eastman, 1994), adolescents were well monitored, with mean scores of $3.28, S D=.53$, for mothers and $3.10, S D=.53$, for fathers. Cronbach's alpha was .83 in the mother sample and .80 in the father sample.

The measure of parental values regarding adolescent alcohol use was adapted from an existing instrument (Wilmes, 1991) that assesses adolescent perceptions of parental values. Parents responded to six statements that examine whether they would make exceptions regarding adolescent alcohol use under various circumstances (e.g., "It is OK for my child to drink at family celebrations," and "If my child did drink once in awhile, I wouldn't get upset"). On a scale of strongly agree (0) to strongly disagree (3), most parents disapproved of adolescent alcohol use, as evidenced by the mean of 2.45 for mothers, $S D=.51$, and 2.31 for fathers, $S D=.54$. The reliabilities were identical for mothers and fathers, Cronbach's alpha $=.90$. We suspect most parents would claim to disapprove of adolescent use of such substances as marijuana, cocaine/crack, or inhalants. Thus, we believe restricting the measurement of parents' values to adolescent alcohol use provides a more sensitive indicator with greater variability.

\section{RESULTS}

\section{Preliminary Analyses}

Descriptive analyses revealed that the drugs of choice among the eighth to twelfth graders in the sample were beer/wine/wine coolers and smoking tobacco. About 3 out of 10 adolescents reported regular use of these substances; specifically, $29 \%$ of adolescents in the mother sample and $28 \%$ in the father sample reported drinking beer, wine, or wine coolers at least one to three times a month, and $28 \%$ of adolescents in the mother sample and $26 \%$ in the father sample reported smoking cigarettes at least one to three times a month. Next in prevalence were hard liquor, 15\% in the mother sample and $14 \%$ in the father sample, and marijuana, $11 \%$ in the mother sample and $9 \%$ in the father sample. Less than $4 \%$ of the adolescents in either sample reported using hallucinogens, chewing tobacco, inhalants, or cocaine/crack on a regular basis.

The correlations among all the study variables were computed. The zero-order correlation coefficients were between 0 and .54 for mothers and 0 and .47 for fathers, indicating no problems of multicollinearity (Table 1). These correlations indicated the relation of the personal characteristics of the adolescent and the parent to adolescent substance use and the parenting measures. For example, in the correlations of child's sex with all the study variables, one significant correlation emerged: Mothers were more apt to disapprove of alcohol use for sons than for daughters. Older adolescents reported higher levels of substance use and relative peer orientation in both the mother and father samples; parents of older adolescents also reported less disapproval of adolescent alcohol use and less parental monitoring than did parents of younger adolescents. For mothers only, higher levels of education were linked to more disapproval of adolescent alcohol use. In the father sample, fathers in two-parent biological or adoptive families reported more monitoring and responsiveness than those in other family types; adolescents also reported more substance use in family types other than two-parent biological or adoptive families. Because child's sex, child's age, parent's education, and family structure were correlated with either adolescent substance use or the parenting measures, these four variables were used as covariates in subsequent analyses. 
Table 1 Correlation Matrix of Substance Use, Parenting Variables, Peer Orientation, and Personal Characteristics in the MotherTeen and Father-Teen Samples

\begin{tabular}{|c|c|c|c|c|c|c|c|c|}
\hline Variables & 1 & 2 & 3 & 4 & 5 & 6 & 7 & 8 \\
\hline \multicolumn{9}{|l|}{ 1. Substance use } \\
\hline \multicolumn{9}{|l|}{$\begin{array}{l}\text { 2. Parental values regard- } \\
\text { ing adolescent alcohol }\end{array}$} \\
\hline $\begin{array}{l}\text { use } \\
\text { 3. Parental monitoring }\end{array}$ & $\begin{array}{l}-.16^{* *} /-.10 \\
-.34^{* *} /-.29^{* *}\end{array}$ & $\begin{array}{c}1.00 \\
.18^{* *} / .24^{* *}\end{array}$ & 1.00 & & & & & \\
\hline 4. Parental responsiveness & $-.15^{* *} /-.08$ & $.09 / .23^{* *}$ & $.54^{* *} / .47^{* *}$ & 1.00 & & & & \\
\hline 5. Relative peer orientation & $.20^{* *} / .18^{* *}$ & $.00 /-.10$ & $-.09 /-.13^{*}$ & $-.18^{* *} /-.16^{*}$ & 1.00 & & & \\
\hline 6. Child's sex & $-.02 /-.08$ & $-.14 * /-.08$ & $.06 / .12$ & $.10 / .03$ & $.10 / .09$ & 1.00 & & \\
\hline 7. Child's age & $.24^{* *} / .21^{* *}$ & $-.24^{* *} /-.25^{* *}$ & $-.18^{* *} /-.17^{* *}$ & $-.04 /-.07$ & $.15^{* *} / .13^{*}$ & $.00 /-.01$ & 1.00 & \\
\hline 8. Parent's education & $-.06 /-.05$ & $.14^{*} / .12$ & $.06 / .10$ & $.07 /-.01$ & $.05 / .04$ & $-.07 /-.02$ & $-.07 /-.07$ & 1.00 \\
\hline 9. Family structure & $-.09 /-.20^{* *}$ & $-.01 / .04$ & $.08 / .18^{* *}$ & $-.04 / .14^{*}$ & $-.04 / .00$ & $-.02 / .10$ & $.08 / .03$ & $.03 / .08$ \\
\hline
\end{tabular}

Path Analyses Examining Mother and Peer Influences on Adolescent Substance Use

A series of regression analyses examined the direct and indirect influences of the parent and peer variables on adolescent substance use in the mother-adolescent data set. In accordance with Baron and Kenny (1986), we first examined the relation of both monitoring and responsiveness to adolescent substance use, while controlling for child's sex, child's age, mother's education, and family structure. As indicated in Table 2, the relation between maternal responsiveness and adolescent substance use was not significant. The relation between monitoring and substance use, however, was significant, with higher levels of maternal monitoring associated with lower levels of adolescent substance use.

Next, we examined the hypothesis that parental values regarding adolescent alcohol use moderate the relation of parental responsiveness and parental monitoring to adolescent substance use (Table 2). Contrary to our prediction, the relation between maternal monitoring and adolescent alcohol use was not moderated by maternal values. Consistent with our prediction, however, the relation between responsiveness and substance use was moderated by maternal values. That is, the significant interaction indicates differences among the slopes; specifically, the relation between maternal responsiveness and adolescent substance use depends on maternal values regarding adolescent alcohol use. In Figure 2, we graph the mean, a high, and a low score on the values scale. To accurately interpret this figure, an im- portant caveat is that mothers typically disapproved of adolescent alcohol use; on average, mothers' score on the values scale was 2.5, the midpoint between 2 (disagree) and 3 (strongly disagree).

Follow-up regression analyses examined whether these slopes representing three scores on the values scale differed significantly from 0 (Aiken \& West, 1991). The slope for the mothers with a mean score of 2.5 on the values scale was unrelated to adolescent substance use. Those mothers who most strongly disapproved of adolescent alcohol use had scores of 3, which resulted from ratings of strongly disagree on all six items. Contrary to our prediction, this slope tended to be positive, $\beta=.11, p=.069$, indicating that higher maternal responsiveness was associated with more substance use. For mothers who scored 1.83 on the values scale, which is still closer to 2 (disagree) than 1 (agree), the slope was negative. For these less disapproving mothers, more maternal responsiveness appeared to be associated with less substance use, although the slope did not differ significantly from 0 .

Next, we regressed relative peer orientation on parental responsiveness, monitoring, and values, as summarized in Table 2. Consistent with our expectations, responsiveness was significantly associated with relative peer orientation. Mothers who reported being more responsive had adolescents who reported lower levels of relative peer orientation. Neither mothers' monitoring nor maternal values regarding adolescent alcohol use were associated with relative peer orientation. As expected, in the next regression, peer orientation was positively associated with adolescent substance use with the 
Table 2 Series of Regressions for Path Model of Parent Influences on Peer Orientation and Adolescent Substance Use

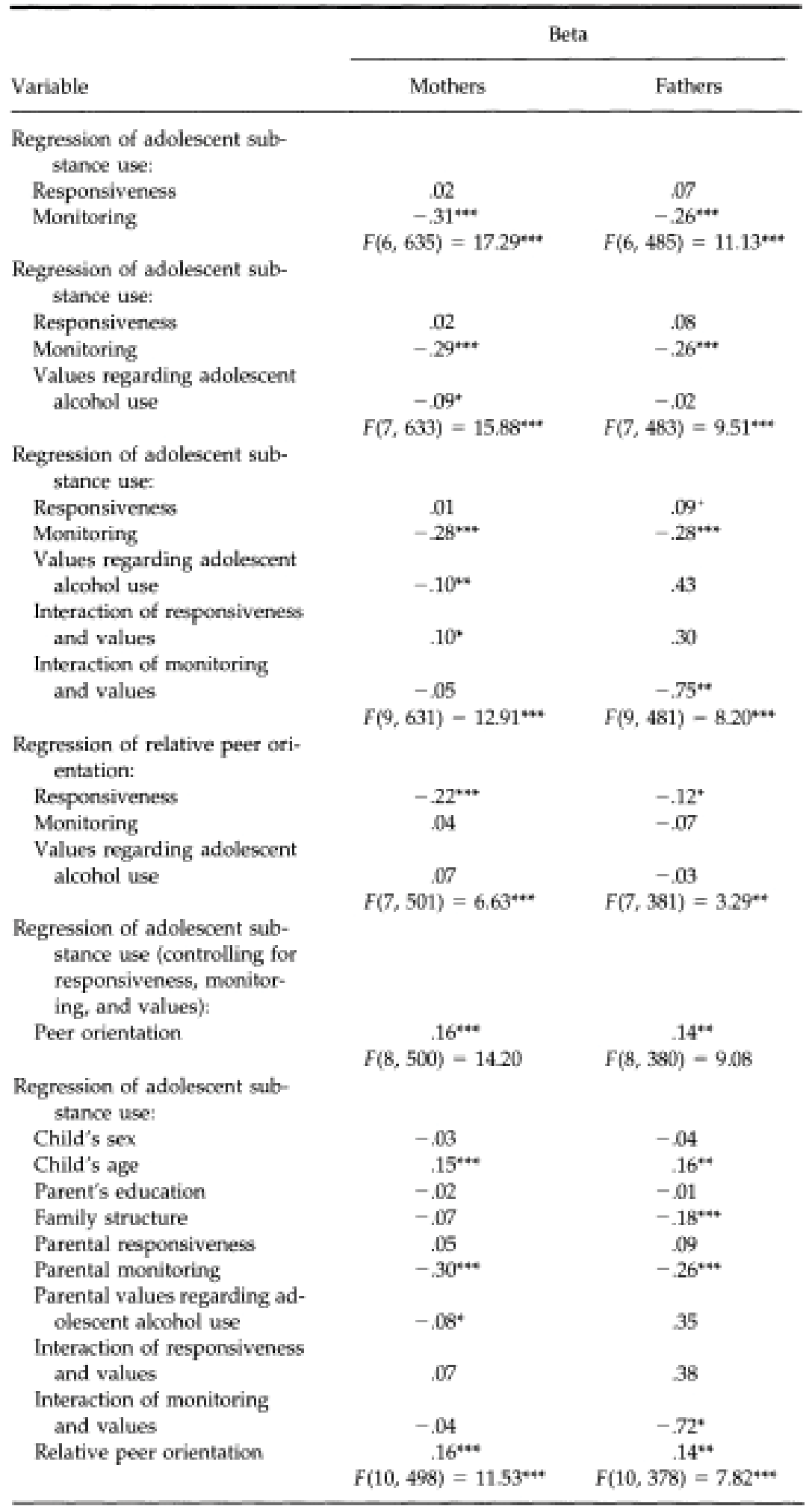

Nate: All models control for child's sex, child's age, parent's education, and family structure.

${ }^{+} p \leq .07 ; * p \leq .06 ; *+p \leq .01 ;{ }^{* *} p \leq .001$. 


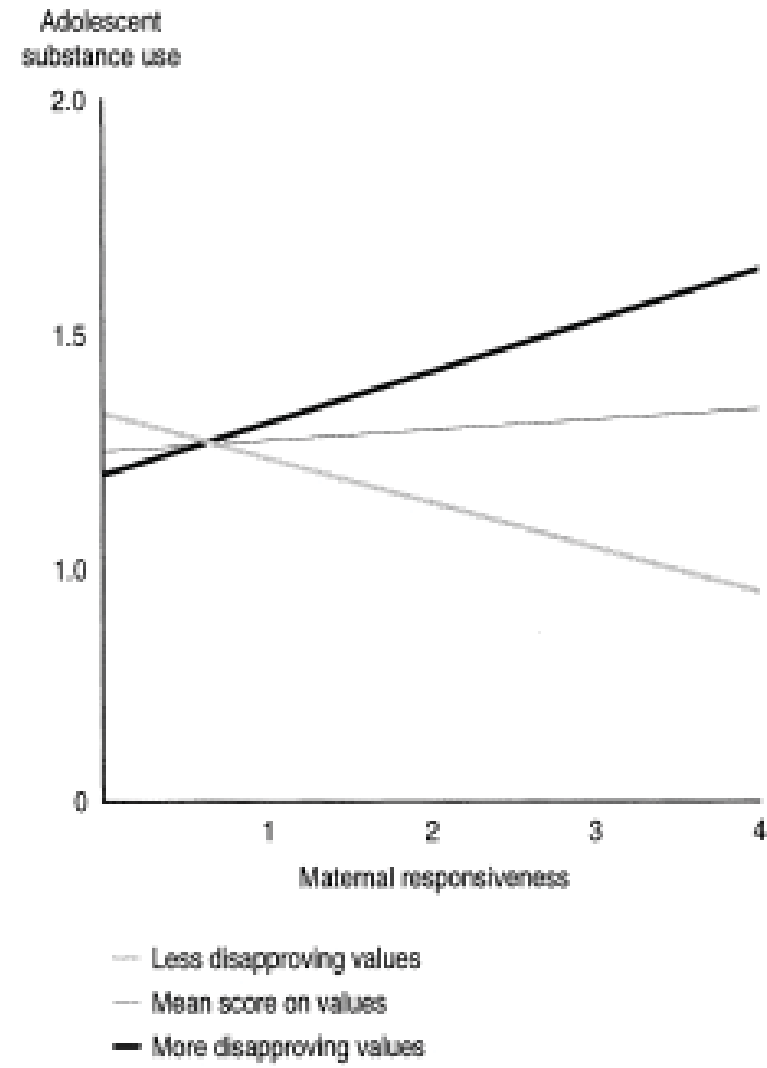

Note. Analyses control for child's sex, child's age, mother's education, and family structure.

Figure 2 The moderating effect of mothers' values regarding adolescent alcohol use on the relation of maternal responsiveness to adolescent substance use.

effects of maternal monitoring, responsiveness, and values partialed out.

In the final analysis, we regressed adolescent substance use on all the other variables and covariates in the model (Table 2). The results displayed in Figure 3 show the mediating process with the paths significant at .05 or better in the final analyses. Consistent with our hypotheses, higher maternal responsiveness was associated with lower relative peer orientation, which in turn was related to lower adolescent substance use. That is, when peer orientation was entered into the analysis, the direct relation between the interaction of maternal responsiveness and values to adolescent substance use disappeared. Thus, maternal responsiveness does not affect substance use directly, but rather indirectly through its association with lower relative peer orientation. The moderator effect indicates that this process does not apply to all mothers in the sample, but depends on maternal values regarding adolescent alcohol use. Thus, it appears that even among those mothers with the most disapproving values on adolescent alcohol use, the tendency for responsiveness to be associated positively with substance use was outweighed by the influence of more responsiveness on less peer orientation. In this final regression, more maternal monitoring and more disapproving maternal values regarding adolescent alcohol use were also directly associated with less substance use. The other significant variable was child's age, with older adolescents reporting more substance use than younger ones.

Path Analyses

Examining Father and Peer Influences on Adolescent Substance Use

A parallel series of regression analyses was conducted for fathers. We first examined the relation of the parenting variables to adolescent substance use, controlling for child's sex, child's age, father's education, and family structure. The hypothesized relation between paternal monitoring and adolescent substance use was significant after controlling for responsiveness and the covariates (Table 2); as predicted, higher levels of paternal monitoring were associated with lower levels of adolescent substance use. Contrary to our hypotheses, however, paternal responsiveness was not associated with adolescent substance use.

Next, we examined the hypothesis that the relation between parenting practices and adolescent substance use would be moderated by paternal values on adolescent alcohol use. Contrary to the results for mothers, the interaction between responsiveness and values was not significant, but the interaction of monitoring and values was. The significant interaction indicates differences among the slopes, as illustrated by the three value scores charted in Figure 4. In follow-up regression analyses examining whether these three slopes differed significantly from 0 (see Aiken \& West, 1991), higher levels of paternal monitoring were associated with less substance use in every instance (for more disapproving fathers with a score of 2.83, $\beta=-.39, p<.001$; for fathers with a mean value of $2.3, \beta$ $=-.27, p<.001$; and for less disapproving fathers with a score of $1.83, \beta=-.16, p<.008)$. To correctly interpret this figure, note that even the less disapproving fathers had scores of 1.83 , which is closer to 2 (disagree) than 1 (agree). As indicated by the betas, the relation of more paternal monitoring to less adolescent substance use is more potent among fathers with more disapproving values regarding adolescent alcohol use. 


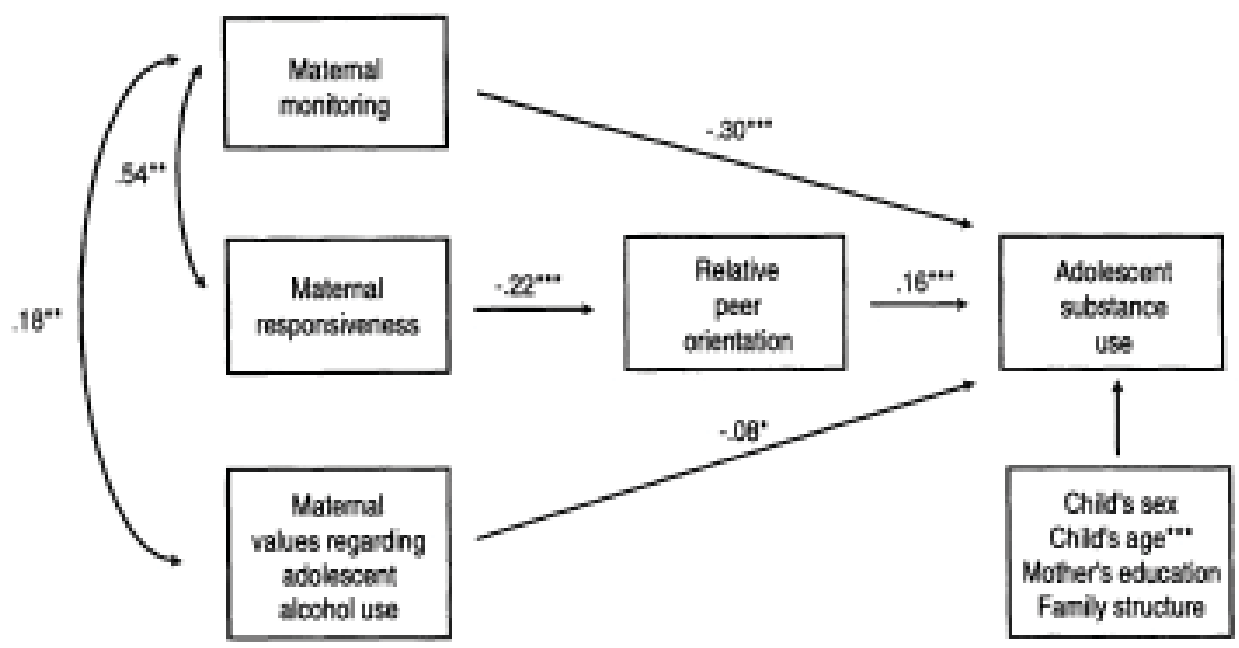

Note .The significant moderating effect of maternal values regarding adolescent alcohol use on adolescent substance use disappeared after relative peer orientation was entered into the analysis. A higher score means more maternal monitoring and responsiveness, and more disapproving values regarding adolescent alcohol use. A higher score means more adolescent substance use, and more orientation to peers relative to parents.

$E(10,483)=11.53^{*+*}, A^{2}=, 19$.

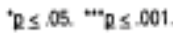

Figure 3 The mediating effect of relative peer orientation on the relation of maternal responsiveness to adolescent substance use

Next, we regressed relative peer orientation on paternal responsiveness, monitoring, and values, as summarized in Table 2. Similar to the results for mothers, responsiveness was significantly related to relative peer orientation; that is, fathers who were warmer and more available had adolescents who reported lower levels of relative peer orientation. The relation between monitoring and relative peer orientation was not significant, however, which means peer orientation cannot mediate the effect of monitoring on substance use. Also, values were not associated with relative peer orientation. As expected, in the next analysis, peer orientation was positively associated with substance use, with monitoring, responsiveness, and values partialed out.

In the final regression, adolescent substance use was regressed on all the major variables in the study and the covariates. The only variables significantly related to adolescent substance use were relative peer orientation, monitoring, the interaction of monitoring and values, child's age, and family structure. As expected, higher peer orientation was associated with more substance use. With peer orientation entered into the analysis, paternal monitoring and the interaction between paternal monitoring and values remained significant in the same direction as in the preceding analyses. The results also indicated higher levels of substance use among older than younger adolescents and more substance use in family types other than two-parent biological or adoptive families. Thus, our hypotheses that fathers' parenting practices would be mediated by relative peer orientation were not confirmed for either paternal responsiveness or monitoring. Our moderating analyses were confirmed for paternal monitoring. More paternal monitoring was associated with less adolescent substance use, with stronger effects among fathers with more disapproving values regarding adolescent alcohol use.

Parent and Child Sex Differences in the Mediating and Moderating Analyses

Based on evidence that mothers and fathers may play different roles with sons and daughters during adolescence (Steinberg, 1990), we examined in post hoc analyses whether the path models described earlier might be influenced by the child's sex. We ran a regression analysis that examined the interaction of child's sex with each independent variable in the model in both the mother and father samples. We entered the control variables and the main effects of each independent variable before entering the interaction terms. The interactions of child's sex with parental responsiveness, parental monitoring, parental values regarding adolescent alcohol use, and relative peer orientation were not significant in the 


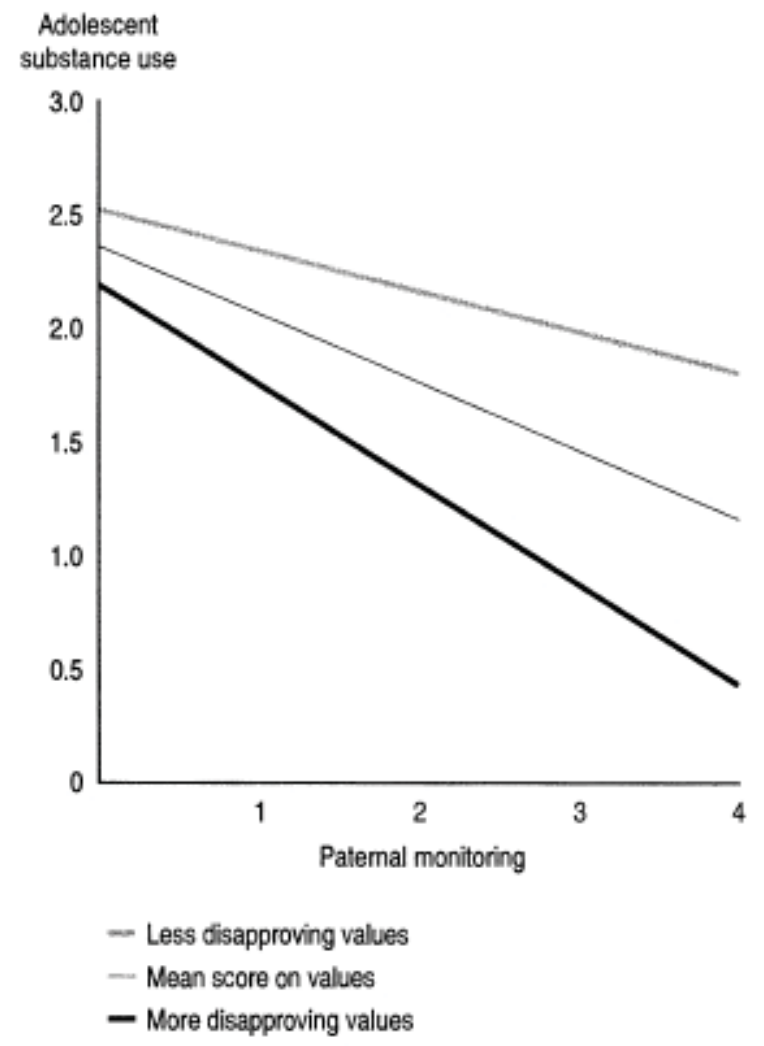

Note. Analyses control for child's sex, child's age, father's education, and family structure.

Figure 4 The moderating effect of fathers' values regarding adolescent alcohol use on the relation of paternal monitoring to adolescent substance use.

mother or father samples. Thus, it was not appropriate to run the analysis separately as a function of child's sex.

\section{DISCUSSION}

In support of the tenets of mesosystem analysis that adolescents' experiences in the family domain may magnify or mitigate experiences in the peer domain (Bronfenbrenner, 1977, 1979), this study finds parenting practices influence adolescents' orientation toward peers, and that experiences in both the parent and peer domains influence the likelihood that adolescents will engage in substance use. These results extend earlier findings in four important ways.

First, consistent with findings among younger children, this study demonstrates that mothers and fathers play an important role in influencing peer relationships, even for offspring as old as high school age. Contrary to theories of weak parent-peer linkages, this study provides support for maternal influence on relative peer orientation and subsequently on an outcome known to be heavily influenced by peers, adolescent substance use.
Second, the results support the propositions of individuation-connectedness theories that the primary mechanism through which parents influence peer orientation is their relationship with their adolescents. Parents influence peer orientation primarily by being responsive to their adolescents in ways such as expressing love or praise, being available when needed, and engaging in give-and-take discussions. Moreover, the results argue against the proposition of socialization theorists that parents influence peer relationships primarily through such monitoring practices as tracking adolescents' whereabouts, discussing adolescents' plans, and becoming acquainted with adolescents' friends and the parents of their friends.

Third, by employing independent measures of parent and peer influence, this study illustrates the pathways through which parents and peers influence adolescent substance use. When mothers reported higher levels of responsiveness, adolescents reported lower orientation to peers, which in turn resulted in lower self-reported adolescent substance use. Yet this pathway did not operate for all mothers in the sample, but was moderated by maternal values regarding adolescent alcohol use. Among fathers, higher levels of monitoring were directly associated with lower levels of adolescent substance use. Yet this proximal process did not apply uniformly to all fathers but was moderated by fathers' values regarding adolescent alcohol use. Thus, even though monitoring by either mothers or fathers is unrelated to peer orientation, it remains an important parenting practice during adolescence because it directly lowers the likelihood that adolescents will engage in substance use. Also, in the final path model for mothers, more disapproving values regarding adolescent alcohol use were directly related to less adolescent substance use.

Fourth, our results confirm earlier findings based solely on adolescent reports that parental strictness and supervision deter involvement in deviant behavior, and that warmth and acceptance contribute to social competence and psychological adjustment (Lamborn et al., 1991). Yet this study extends these findings by suggesting that parental influences on adolescent development may be moderated by the value parents place on particular socialization outcomes. For example, significant differences were found among mothers in the relation of responsiveness to adolescent substance use. Among mothers who were less disapproving of adolescent alcohol use in certain circumstances (e.g., at family celebrations, as long as the adolescent does not drive; when parents are present), the slope was negative as predicted, with more maternal 
responsiveness associated with less adolescent substance use; the slope, however, did not differ significantly from 0 . Yet among mothers who were the most disapproving of adolescent alcohol use in every circumstance, the direction of the slope reversed, with more responsiveness tending to be associated with more substance use. Although the pattern of these most disapproving mothers is contrary to our expectations, upon reflection, it may be consistent with the tenets of individuation-connectedness theory. Parents who are unable to make any exceptions regarding a normative behavior like adolescent alcohol use may also be unable to allow the parent-child relationship to transform in other ways that allow the adolescent opportunities to demonstrate maturity and self-direction. As Ginott (1969) indicated, adolescents seem to have an inner radar for detecting strongly held parental values, which may become an obvious target for pushing limits and demonstrating independence from parents.

Parental values also influenced paternal monitoring, with stronger effects on adolescent substance use among fathers who held values more disapproving of adolescent alcohol use than among those with less disapproving values. Thus, the influence of parenting practices on adolescent behaviors appears to be moderated by parental values. In other words, the potency of parenting practices, even those widely recognized as effective during adolescence, appears to be preempted by the values parents hold regarding how desirable or appropriate specific adolescent behaviors are deemed to be.

These findings have theoretical, methodological, and pragmatic implications. Several theories, including "two social worlds," socialization, and psychoanalytic, advance a view of parents as impotent in influencing their children's peer relationships, suggesting that parents have "more to lose than gain in their child-rearing practices during adolescence" (Brown \& Huang, 1995, p. 24). The results of this study call into question views that the parent-child relationship is repudiated during adolescence or operates in isolation from relationships with peers. Instead of distinct, detached, or antagonistic linkages between parents and peers, the results suggest a more mutual, contingent, and interactive view of parent-peer linkages during adolescence. Moreover, this mutuality between parents and peers appears to derive from characteristics of the parent-child relationship, as proposed by individualconnectedness theorists, not from parental monitoring, as proposed by socialization theorists.

These results, although supporting theories of strong parent-peer linkages, do not presuppose that all parents are able to maintain close relationships with their adolescents against a backdrop of increasing autonomy. Based on the primarily European American respondents in this study, parents are able to maintain close relationships, which brings with it the advantage of being able to restrain adolescents from extreme peer orientation. Yet undoubtedly, in some families or circumstances, a history of distance in the parent-child relationship may be too ingrained to be overcome at adolescence, thereby resulting in parental disengagement, detachment, or abdication of responsibility. Thus, even though the results suggest many families can influence adolescent peer relationships, we can in no way conclude that these findings hold across all families, regardless of relationship history, racial/ethnic origin, or socioeconomic status.

Conceivably, parents who chose not to participate in the study may be more likely to have difficult relationships with their children. The unique nature of the data set allowed us to compare adolescents whose parents did not participate with those who did. Consistent with results of longitudinal studies, our findings indicate that families with antisocial children were least apt to participate (Snyder et al., 1986). Students whose parents did not participate reported lower grade point averages, higher substance use, and more instances of running away from home in the past year. Moreover, adolescents whose parents did not participate were significantly more likely to be in a special education or alternative class, from an ethnic minority group, and not living with two biological parents.

Methodologically, the findings suggest that studies of parent-adolescent relationships would benefit by examining processes whereby parental values translate into child outcomes. According to Darling and Steinberg (1993, p. 492), "the values parents hold and the goals toward which they socialize their children are critical determinants of parenting behavior." Contrary to this contention that parental values play a causal role in defining the practices parents employ, the results of our study raise the intriguing possibilities that parental values directly affect adolescent outcomes or moderate the efficacy of parenting practices. That is, our results suggest that parenting practices may not be generic in their effectiveness, but may depend, in part, on the value parents place on particular socialization outcomes. For example, paternal monitoring is related more strongly to lower adolescent substance use among fathers who are more disapproving of 
adolescent alcohol use than among those who are less disapproving. If parents ascribe to permissive values regarding adolescent alcohol use, it should come as no surprise that monitoring is less effective in minimizing adolescent substance use. Yet the results for mothers' responsiveness suggest that if values are too extreme, they may backfire and encourage the behavior they intend to discourage.

Regardless of the mechanisms whereby parental values influence adolescent outcomes, the tacit neglect of parental values in most studies may explain inconsistent findings and the low amount of variance accounted for by parenting variables during adolescence (Fuligni \& Eccles, 1993; Lamborn et al., 1991). The assumption that adolescent outcomes like academic prowess, social skills, and sexual abstinence are valued equally by all parents results in findings that reflect accurately the sample as a whole, but may misrepresent the reality of the diverse parent population, some who highly value an outcome and some who do not.

Another methodological implication is that studies of parent-peer linkages may benefit if the data derive from both parents and adolescents, who may view family processes differently (Barnes \& Farrell, 1992). With data from both sources, parent and peer influences are less apt to be conceived as endpoints of a single dimension and more apt to be viewed as separate orthogonal dimensions (Rigsby \& McDill, 1975). Interestingly, studies based on adolescent data have tended to report weaker influences of parents on peer relationships (see Berndt, 1979; Brown \& Huang, 1995; Fuligni \& Eccles, 1993; Steinberg \& Silverberg, 1986) than this study and others with parent data (Cooper \& Cooper, 1992; Kandel \& Andrews, 1987). Adolescents, who are striving to become more autonomous from parents, might be less willing to acknowledge their parents' influence on their behavior than parents assert; this study suggests that parents' more substantial claims may be well founded.

Pragmatically, these findings suggest that those who educate or provide services to families should refrain from overestimating the negative influence of peers and underestimating the positive influence of parents (Steinberg \& Brown, 1989). Based on this study, parent educators should recommend that, when it comes to peer relationships, parents should not "buzz off" but instead "butt in" by being responsive and available to their adolescents. Research suggests that even distressed families can learn such specific child management practices as monitoring and responsiveness through parent education classes (Ka- zdin, 1987; Patterson, 1986) and age-paced parent education newsletters (Bogenschneider \& Stone, 1997).

Future research needs to build on the five inherent limitations of this study. First, an important caveat is that the consistency of the findings with the theoretical model does not prove the theory, but rather provides support for it (Kerlinger \& Pedhazur, 1973). Second, longitudinal research is needed to delineate more clearly the processes that link the parent and peer domains. For example, are the processes indirect (Ladd, 1992; Parke \& Bhavnagri, 1989), as this study suggests; in other words, do parenting practices targeted toward particular goals (e.g., maintaining a responsive relationship with adolescents) also serve other purposes (e.g., reducing adolescents' susceptibility to extreme peer orientation)? In addition, as others have suggested, do parents take deliberate steps to directly manage their adolescents' peer relationships by offering advice on how to develop and maintain friendships and by setting limits on interactions with less desirable friends (Brown, Hamm, \& Meyerson, 1996; Kraft, 1995; Mounts, 1996; Parke \& Bhavnagri, 1989)? A third limitation is that the cross-sectional nature of the data does not allow a clear interpretation of the findings. The path model implies, for example, that less involved parenting leads to more adolescent substance use, whereas the reverse could be true-more substance use could lead to less involved parenting. Without longitudinal data, it is also impossible to determine whether parental responsiveness initiated during adolescence has the benefits observed in this study, or whether the benefits accrue only if parental responsiveness is initiated during childhood and continued through adolescence. Fourth, more study is needed to replicate in the peer domain the fine-tuned distinctions we have made in the parent domain. We fully expect that adolescents hold divergent values about risky and prosocial behaviors and that peer influence is not a unitary force that is primarily negative in its influence (Brown \& Huang, 1995). Fifth, these results raise the intriguing possibility that mothers and fathers may assume responsibility for different parenting functions during adolescence. In future analyses, we plan to disentangle whether adolescent outcomes are affected by variations in the family level of a parenting practice (e.g., whether thresholds exist above which no additional benefits accrue, and discrepancies between child and parent reports).

Finally, this study supports theories of strong parentpeer linkages, providing evidence that adolescence is not a time for parents to disengage, but rather a time to re- 
main involved and connected. One of the greatest legacies parents may pass on to their children is the influence they have, through the interface of their values and practices, on their children's capacity to resist extreme peer orientation (Rubin \& Sloman, 1984) and avoid risky behaviors.

\section{ACKNOWLEDGMENTS}

The authors thank B. Bradford Brown for comments on an early draft of this manuscript, the parents and students who participated in this study, and the faculty and staff from three school districts for their co-operation and support. The assistance of Elizabeth Ragsdale and Meg Wall-Wild in manuscript preparation is gratefully acknowledged. This research was made possible through financial support provided to the first author by the U.S. Department of Agriculture-Extension Service, Elizabeth C. Davies, and Land o' Lakes. An earlier version of this paper was presented at the 1996 biennial meeting of the Society for Research on Adolescence in Boston, MA.

\section{ADDRESSES AND AFFILIATIONS}

Corresponding author: Karen Bogenschneider, 201a Child \& Family Studies, University of Wisconsin-Madison, 1430 Linden Drive, Madison, WI 53706; e-mail:kpbogens@facstaff.wisc.edu . Ming-yeh Wu is at Soochow University, Taipei; Marcela Raffaelli is at the University of Nebraska-Lincoln; and Jenner C. Tsay is at the University of Wisconsin-Madison.

\section{REFERENCES}

Aiken, L. S., \& West, S. G. (1991). Multiple regression: Testing and interpreting interactions. Newbury Park, CA: Sage.

Armsden, G., \& Greenberg, M. T. (1987). Inventory of parent and peer attachment: Individual differences in their relationship to psychological well-being in adolescence. Journal of Youth and Adolescence, 16, 427-453.

Ary, D. V., Tildesley, E., Hops, H., Lichtenstein, E., \& Andrews, J. (n.d.). The influence of parent, sibling, and peer modeling and attitudes on adolescent use of cigarettes, alcohol, and marijuana. Eugene: Oregon Research Institute.

Barnes, G. M., \& Farrell, M. P. (1992). Parental support and control as predictors of adolescent drinking, delinquency, and related problem behaviors. Journal of Marriage and the Family, 54, 763-776.

Barnes, G. M., Farrell, M. P, \& Banerjee, S. (1994). Family influences on alcohol abuse and other problem behaviors among black and white adolescents in a general population sample. Journal of Research on Adolescence, 4, 183-201.
Barnes, G. M., \& Welte, J. W. (1986). Patterns and predictors of alcohol use among $7^{\text {th }}-12$ th grade students in New York State. Journal of Studies on Alcohol, 47, 53-61.

Baron, R. M., \& Kenny, D. A. (1986). The moderator-mediator variable distinction in social psychological research: Conceptual, strategic, and statistical considerations. Journal of Personality and Social Psychology, 51, 1173-1182.

Baumrind, D. (1967). Child care practices anteceding three patterns of preschool behavior. Genetic Psychology Monographs, 75, 43-88.

Belle, D. (1989). Gender differences in children's social networks and supports. In D. Belle (Ed.), Children's social networks and social supports (pp. 1-12). New York: Wiley.

Belsky, J., Hertzog, C., \& Rovine, M. (1986). Causal analyses of multiple determinants of parenting: Empirical and methodological advances. In M. Lamb, A. Brown, \& B. Rugoff (Eds.), Advances in developmental psychology (Vol. 4, pp. 153-202). Hillsdale, NJ: Erlbaum.

Belsky, J., Steinberg, L., \& Draper, P. (1991). Childhood experience, interpersonal development, and reproductive strategy: An evolutionary theory of socialization. Child Development, 62, 647-670.

Berndt, T. J. (1979). Developmental changes in conformity to peers and parents. Developmental Psychology, 15, 606-616.

Blos, P. (1979). The adolescent passage. New York: International Universities Press.

Bogenschneider, K., \& Stone, M. (1997). Delivering parent education to low and high risk parents of adolescents via agepaced newsletters. Family Relations, 46, 123-134.

Bogenschneider, K., Wu, M.-Y., Raffaelli, M., \& Tsay, J. C. (1998). Other teens drink, but not my kid: Does parental awareness of adolescent alcohol use protect adolescents from risky consequences? Journal of Marriage and the Family, 60, 356-373.

Brody, G. H., \& Shaffer, D. R. (1982). Contributions of parents and peers to children's moral socialization. Developmental Review, 2, 31-75.

Bronfenbrenner, U. (1977, July). Toward an experimental ecology of human development. American Psychologist, pp. 513-531.

Bronfenbrenner, U. (1979). The ecology of human development. Cambridge, MA: Harvard University Press.

Brook, J. S., Whiteman, M., Gordon, A. S., \& Cohen, P. (1986). Some models and mechanisms for explaining the impact of maternal and adolescent characteristics on adolescent stage of drug use. Developmental Psychology, 22, 460-467.

Brown, B. B. (1996). Buzz off or butt in: Parental involvement in adolescent peer relationships. Symposium organized for the biennial meetings of the Society for Research on Adolescence, Boston, MA.

Brown, B. B., Hamm, J. V., \& Meyerson, P. (1996). Encouragement, empowerment, detachment: Ethnic differences in approaches to parental involvement with peer relationships. Paper presented at the biennial meeting of the Society for Research on Adolescence, Boston, MA. 
Brown, B., \& Huang, B.-H. (1995). Examining parenting practices in different peer contexts: Implications for adolescent trajectories. In L. J. Crockett \& A. C. Crouter (Eds.), Pathways through adolescence (pp. 2-37). Mahwah, NJ: Erlbaum.

Brown, B. B., Mounts, N., Lamborn, S. D., \& Steinberg, L. (1993). Parenting practices and peer group affiliation in adolescence. Child Development, 64, 467-482.

Carlson, C. I., Cooper, C. R., \& Spradling, V. Y. (1991). Developmental implications of shared versus distinct perceptions of the family in early adolescence. New Directions for Child Development, 51, 13-32.

Clausen, J. A. (Ed.). (1968). Socialization and society. Boston: Little, Brown.

Cleary, P. D., \& Kessler, R. C. (1982). The estimation and interpretation of modifier effects. Journal of Health and Social Behavior, 23, 159-169.

Cohen J. S., \& Woody, E. Z. (1991, April). Maternal involvement in children's peer relationships: The contribution of mothers' experiences, values and beliefs. Paper present at the biennial meeting of the Society for Research in Child Development, Seattle, WA.

Coleman, J. S. (1960). The adolescent subculture and academic achievement. American Journal of Sociology, 65, 337-347.

Collins, W. A. (1990). Parent-child relationships in the transition to adolescence: Continuity and change, interaction, affect, and cognition. In R. Montemayer, G. R. Adams, \& T. P. Gullotta (Eds.), From childhood to adolescence: A transitional period? (pp. 85-106). Newbury Park, CA: Sage.

Cooper, C. R., \& Cooper, R. G. (1992). Links between adolescents' relationships with their parents and peers: Models, evidence, and mechanisms. In R. D. Parke \& G. W. Ladd (Eds.), Family-peer relationships: Modes of linkage. Hillsdale, NJ: Erlbaum.

Darling, N., \& Steinberg, L. (1993). Parenting style as context: An integrative model. Psychological Bulletin, 113, 487-496.

Eastman, G. (1994). Maternal employment, parental monitoring, and adolescent drinking: A process study. Unpublished doctoral dissertation, Cornell University, Ithaca, NY.

Freud, A. (1958). Adolescence. Psychoanalytic Study of the Child, 13, 255-278.

Fuligni, A. J., \& Eccles, J. S. (1993). Perceived parent-child relationships and early adolescents' orientation towards peers. Developmental Psychology, 29, 622-632.

Gecas, V., \& Seff, M. A. (1990). Families and adolescents: A review of the 1980s. Journal of Marriage and the Family, 52, 941-958.

Ginott, H. G. (1969). Between parent and teenager. New York: Macmillan.

Glynn, T. J. (1981). From family to peer: A review of transitions of influence among drug-using youth. Journal of Youth and Adolescence, 10, 363-383.

Greenberg, M. T., Siegel, J. M., \& Leitch, C. J. (1983). The nature and importance of attachment relationships to parents and peers during adolescence. Journal of Youth and Adolescence, 12, 373-386.

Hawkins, J. D., Catalano, R. F., \& Miller, J. Y. (1992). Risk and protective factors for alcohol and other drug problems in adolescence and early adulthood: Implications for substance abuse prevention. Psychological Bulletin, 112, 64-105.

Heise, D. R. (1975). Causal analysis. New York: Wiley.

Hundleby, J. D., \& Mercer, G. W. (1987, February). Family and friends as social environments and their relationship to young adolescents' use of alcohol, tobacco, and marijuana. Journal of Marriage and the Family, 49, 151-164.

Irwin, C. E., Jr., \& Millstein, S. G. (1986). Biopsychosocial correlates of risk-taking behaviors during adolescence: Can the physician intervene? Journal of Adolescent Health Care, 7, 82S-96S.

Kandel, D. B. (1986). Processes of peer influences in adolescence. In R. K. Silbereisen, K. Eyferth, \& G. Rudinger (Eds.), Development as action in context: Problem behavior and normal youth development (pp. 203-228). New York: SpringerVerlag.

Kandel, D. B., \& Andrews, K. (1987). Processes of adolescent socialization by parents and peers. International Journal of the Addictions, 22, 319-342.

Kandel, D. B., Kessler, R. C., \& Margulies, R. Z. (1978). Antecedents of adolescent initiation into stages of drug use: A developmental analysis. In D. B. Kandel (Ed.), Longitudinal research and drug use: Empirical findings and methodological issues (pp. 73-98). Washington, DC: Hemisphere.

Kazdin, A. E. (1987). Treatment of antisocial behavior in children: Current status and future directions. Psychological Bulletin, 102, 187-203.

Kerlinger, F. N., \& Pedhazur, E. J. (1973). Multiple regression in behavioral research. New York: Holt, Rinehart \& Winston.

Kohn, M. L. (1969). Class and conformity: A study in values. Homewood, IL: Dorsey.

Kraft, L. L. (1995). The development of a measure of parental involvement in adolescent peer relations. Unpublished masters thesis, University of Wisconsin-Madison.

Ladd, G. W. (1992). Themes and theories: Perspectives on processes in family-peer relationships. In R. D. Parke \& G. W. Ladd (Eds.), Family-peer relationships: Modes of linkage (pp. 3-34). Hillsdale, NJ: Erlbaum.

Lamborn, S. D., Mounts, N. S., Steinberg, L., \& Dornbusch, S. M. (1991). Patterns of competence and adjustment among adolescents from authoritative, authoritarian, indulgent, and neglectful families. Child Development, 62, 1049-1065.

Maccoby, E. E., \& Martin, J. A. (1983). Socialization in the context of the family: Parent-child interaction. In E. M. Hetherington (Ed.), P. H. Mussen (Series Ed.), Handbook of child psychology: Vol. 4. Socialization, personality, and social development (4th ed., pp. 1-101). New York: Wiley.

McCord, J. (1990). Problem behaviors. In S. S. Feldman \& G. R. Elliott (Eds.), At the threshold: The developing adolescent (pp. 414-430). Cambridge, MA: Harvard University Press. 
Miller, B. C. (1993). Families, science, and values: Alternative views of parenting effects and adolescent pregnancy. Journal of Marriage and the Family, 55, 7-21.

Minuchin, P. (1985). Families and individual development: Provocations from the field of family therapy. Child Development, $56,289-302$.

Mounts, N. (1996). Parental attempts to control adolescents' friendships: Do they have an effect on friend selection? Paper presented at the biennial meeting of the Society for Research on Adolescence, Boston, MA.

Muuss, R. E. (1988). Theories of adolescence (5th ed.). New York: Random House.

Newcomb, M. D., \& Bentler, P. M. (1989). Substance use and abuse among children and teenagers. American Psychologist, 44, 242-248.

Norem-Hebeisen, A., Johnson, D. W., Anderson, D., \& Johnson, R. (1984). Predictors and concomitants of changes in drug use patterns among teenagers. Journal of Social Psychology, $124,43-50$.

Olson, D. H., McCubbin, H., Barnes, H. L., Larson, A. S., Muxen, M. J., \& Wilson, M. A. (1983). Families: What makes them work. Beverly Hills, CA: Sage.

Parke, R. D., \& Bhavnagri, N. P. (1989). Parents as managers of children's peer relationships. In D. Belle (Ed.), Children's social network and social support (pp. 241-259). New York: Wiley.

Pasley, K., \& Gecas, V. (1984, March). Stresses and satisfactions of the parental role. Personnel and Guidance Journal, pp. $400-404$.

Patterson, G. R. (1986). Performance models for antisocial boys. American Psychologist, 41, 432-444.

Patterson, G. R., DeBaryshe, B. D., \& Ramsey, E. (1989). A developmental perspective on antisocial behavior. American Psychologist, 44, 329-335.

Patterson, G. R., \& Stouthamer-Loeber, M. (1984). The correlation of family management practices and delinquency. Child Development, 55, 1299-1307.

Piaget, J. (1965). The moral judgment of the child. New York: Free Press. (Original work published 1932).

Renshaw, P. D., \& Parke, R. D. (1992). Family and peer relationships in historical perspective. In R. D. Parke \& G. W. Ladd (Eds.), Family-peer relationships: Modes of linkage (pp. 3574). Hillsdale, NJ: Erlbaum.

Rigsby, L. C., \& McDill, E. L. (1975). Value orientations of high school students. In H. R. Stub (Ed.), The sociology of education: A sourcebook (pp. 53-75). Homewood, IL: Dorsey.

Rosnow, R. L., \& Rosenthal, R. (1989). Definition and interpretation of interaction effects. Psychological Bulletin, 105,143146.

Rubin, Z., \& Sloman, J. (1984). How parents influence their children's friendships. In M. Lewis (Ed.), Beyond the dyad (pp. 223-250). New York: Plenum.
Ryan, R. M., \& Lynch, J. H. (1989). Emotional autonomy versus detachment: Revisiting the vicissitudes of adolescence and young adulthood. Child Development, 60, 340- 356.

Small, S., Eastman, G., \& Cornelius, S. (1988). Adolescent autonomy and parental stress. Journal of Youth and Adolescence, 17, 377-392.

Small, S. A., \& Kerns, D. (1993). Unwanted sexual activity among peers during early and middle adolescence: Incidence and risk factors. Journal of Marriage and the Family, 55, 941-952.

Smetana, J. G., \& Asquith, P. (1994). Adolescents' and parents' conceptions of parental authority and personal autonomy. Child Development, 65, 1147-1162.

Snyder, J., Dishion, T. J., \& Patterson, G. R. (1986). Determinants and consequences of associating with deviant peers during preadolescence and adolescence. Journal of Early Adolescence, 6, 29-43.

Steinberg, L. (1987). The impact of puberty on family relations. Effects of pubertal status and pubertal timing. Developmental Psychology, 23, 451-460.

Steinberg, L. (1990). Autonomy, conflict, and harmony in the family relationship. In S. S. Feldman \& G. R. Elliott (Eds.), At the threshold: The developing adolescent (pp. 255- 276). Cambridge, MA: Harvard University Press.

Steinberg, L., \& Brown, P. B. (1989). Beyond the classroom: Parental and peer influences on high school achievement. Paper presented at the annual meeting of the American Educational Research Association, San Francisco, CA.

Steinberg, L., \& Silverberg, S. B. (1986). The vicissitudes of autonomy in early adolescence. Child Development, 57, 841851.

Sullivan, K., \& Sullivan, A. (1980). Adolescent-parent separation. Developmental Psychology, 16, 93-99.

White, K. M., Speisman, J. C., \& Costos, D. (1983, December). Young adults and their parents: Individuation to mutuality. In H. D. Grotevant \& C. R. Cooper (Eds.), Adolescent development in the family. New directions for child development (Vol. 22, pp. 61-76). San Francisco: Jossey-Bass.

Wilmes, D. (1991, June 4-6). Blame parents for teen drinking? USA Today.

Wu, M.-Y. (1995). Reconceptualizing parental control and its relationship to adolescent academic success and involvement in fighting behavior. Unpublished doctoral dissertation, University of Wisconsin-Madison.

Youniss, J., \& Smollar, J. (1985). Adolescent relations with mothers, fathers, and friends. Chicago: University of Chicago Press. 